\title{
Characterization of $\mathrm{PMMA}_{\mathrm{BaTiO}}$ Composite Layers Through Printed Capacitor Structures for Microwave Frequency Applications
}

\author{
Omodara Gbotemi ${ }^{\circledR}$, Sami Myllymäki, Jani Kallioinen, Jari Juuti, Merja Teirikangas, Heli Jantunen, \\ Marjeta Maček Kržmanc, Danilo Suvorov, Marcin Sloma, and Malgorzata Jakubowska
}

\begin{abstract}
This paper presents the extraction of microwave properties of low-temperature cured inorganic composite materials based on barium titanate $\left(\mathrm{BaTiO}_{3}\right)$. These composite materials exhibit attractive features such that when the volume fraction of the filler contents varied, its electrical properties of high permittivity and moderately low loss tangent can be manipulated to suit different areas of applications. For the extraction of the permittivity and the loss tangent, three different ink particles were developed and printed on the top of interdigitalshaped microwave capacitor. The properties of the inks were extracted from measured results through computer simulations. The obtained results were verified with several types of interdigital capacitor structures of different fingers and linewidths. The effect of the thickness of the ink layer materials on the top of the capacitor structures was likewise investigated. The results show relative permittivity $\left(\varepsilon_{r}\right)$ values of 30,25 , and 27 for composite layers printed using inks with Pr. A shape at 67.4 wt \% (percentage by weight), Pr. B shape at 66.3 wt \%, and Pr. C shape at $67.1 \mathrm{wt} \%$ of $\mathrm{BaTiO}_{3}$, respectively, at $2 \mathrm{GHz}$. Corresponding loss tangents $(\tan \delta$ ) were $0.065,0.040$, and 0.025. The dielectric properties of the composite materials are influenced by the thickness variation of the ink layers on the capacitor structures. This novel capacitor composite materials would be a promising candidate for printed application in mobile telecommunication operations, especially in the frequency range of $0.5-3 \mathrm{GHz}$.
\end{abstract}

Index Terms-Barium titanate $\left(\mathrm{BaTiO}_{3}\right)$, microwave, printed interdigital capacitor, RF passives, screen printing.

Manuscript received May 9, 2017; revised October 23, 2017; accepted November 12, 2017. Date of publication February 6, 2018; date of current version April 3, 2018. This work was supported in part by Tekes, Finland, in part by Sachtleben Pigments Oy, Finland, in part by Pulse Finland Oy, Finland, in part by NOF Corporation Japan, and in part by the Academy of Finland under Grant 267573 and Grant 273663. (Corresponding author: Omodara Gbotemi.)

O. Gbotemi, S. Myllymäki, J. Juuti, M. Teirikangas, and H. Jantunen are with the Microelectronics Research Unit, University of Oulu, Oulu, Finland (e-mail: gomodara@student.oulu.fi; samby@ee.oulu.fi; jajuu@ ee.oulu.fi; merja@ee.oulu.fi; heja@ee.oulu.fi).

J. Kallioinen is with Tioxide Europe Ltd. (e-mail: Jani.kallioinen@huntsman.com).

M. M. Kržmanc and D. Suvorov are with the Jožef Stefan Institute, Ljubljana, Slovenia (e-mail: marjeta.macek@ijs.si; danilo.suvorov@ijs.si).

M. Sloma and M. Jakubowska are with the Department of Silicon Technonoly, Institute of Electronic Materials Technology, 01-919 Warsaw, Poland (e-mail: malgorzata.jakubowska@itme.edu.pl; marcin.sloma@ mchtr.pw.edu.pl).

Color versions of one or more of the figures in this paper are available online at http://ieeexplore.ieee.org.

Digital Object Identifier 10.1109/TMTT.2017.2781694

\section{INTRODUCTION}

$\mathbf{T}$ HE use of printing as a technique for the realization of large-area and low-cost electronic systems has recently gained a remarkable level of interest in the microelectronics industry.

Printed electronics offers several benefits over traditional electronics such as transparency, flexibility, and less costly fabrication, and it is growing more rapidly. Printing is expected to further support the realization of electronics on flexible and considerably cheap substrates such as metal foils and plastic [1]. Essentially, the increased need for energyefficient products with tremendous performance and costeffective manufacturing is stimulating the advancement of overall printed electronics market [2]. The technology is deployed and under investigations in several applications such as sensors [3]-[5], radio frequency circuits [6]-[9], solar cells [10], antennas [11], [12], and other electronic components like displays [13]. To realize these systems, it is necessary to develop printable materials with low loss and sufficient permittivity values, especially for high-frequency applications [14]. Functional materials with suitable low loss and high relative permittivity do already exist, but they are high-temperature sintered [15], [16]. The high-temperature sintering or sputtering methods limit their practical usage on the flexible organic substrate. Thus, low curing temperature materials with considerable electrical properties are needed.

Lately, several studies have been carried out in the field of dielectric properties of polymer-ferroelectric ceramic composites [17]-[23]. Some of the possible commercially available of polymer-ceramic composites are polystyrene, polyethlene, peek, PTFE as matrix materials with fillers such as alumina, glasses, titania, and silica [15]. Wang et al. [24] prepared polyimide/barium titanate $\left(\mathrm{BaTiO}_{3}\right)$ composite with different $\mathrm{BaTiO}_{3}$ contents from 0 to $90 \mathrm{wt} \%$ (0-67.5 vol.\%), which yielded relative permittivity ranging from 3.53 to 46.50 and loss tangent from 0.005 to 0.015 at the frequency of $10 \mathrm{kHz}$. Balaraman et al. [25] utilized hydrothermal process $\left(<100{ }^{\circ} \mathrm{C}\right)$ for the production of $\mathrm{BaTiO}_{3}$ on titanium foils and measured to have a capacitance per area varying from 20 to $600 \mathrm{nF} / \mathrm{cm}^{2}$ at $100 \mathrm{kHz}$ with a loss tangent ranging from 0.03 to 0.8 . Chameswary et al. [15] reported the dielectric properties of $\mathrm{BaTiO}_{3}$ butyl rubber 
filled composite processed at temperature $200{ }^{\circ} \mathrm{C}$. The composite exhibited relative permittivity of 3.5 , loss tangent of 0.005 with $10 \mathrm{vol} \%$, permittivity of 8 , and loss tangent of 0.02 with 30 vol.\% at $5 \mathrm{GHz}$ [15]. Composite ink properties of $\mathrm{BaTiO}_{3}$ - poly (vinylidenefluoride-trifluoroethyene) were reported in [26]. The realized permittivity and loss tangent of the composite material measured at $1 \mathrm{MHz}$ were 46 and 0.15 , respectively. Balaraman et al. [25] reported $\mathrm{S}_{\mathrm{rX}} \mathrm{La}_{(1-x)} \mathrm{T}_{\mathrm{ix}} \mathrm{Al}_{(1-x)} \mathrm{O}_{3}$ ceramic with $\mathrm{CaO}-\mathrm{B}_{2} \mathrm{O}_{3}$ glass additive shown lower sintering temperature from $1550{ }^{\circ} \mathrm{C}$ to $1100{ }^{\circ} \mathrm{C}$ and had a dielectric permittivity, quality factor, and temperature dependence of permittivity $\left(\varepsilon_{r} \sim 43.3, Q \times f \sim\right.$ $10780 \mathrm{GHz}$, and $\tau f \sim 20.8 \mathrm{ppm} /{ }^{\circ} \mathrm{C}$ ). Popielarz et al. [28] investigated also the dielectric properties of $\mathrm{BaTiO}_{3}$-polymer composites over a wide frequency range from $100 \mathrm{~Hz}$ to $10 \mathrm{GHz}$ at temperature range from -140 to $+150{ }^{\circ} \mathrm{C}$.

The motivation behind the study presented in this paper is to develop composite material with low loss and low curing temperature for radio and microwave field. In addition, composite material could also be manipulated into preferred properties and structures depending on the type of the component under design. This kind of material would be desirable for electronics miniaturization purposes and for improving the electrical properties of printed components and devices, such as antenna, matching circuits, filters, transmission lines, and resonators.

In this paper, $\mathrm{BaTiO}_{3}$ was chosen as an integrating material based on its high-performance properties of low loss tangent, and high relative permittivity at room temperature, which makes it most widely used material especially in electronics device like ceramic capacitors [21]. Three different shaped and processed $\mathrm{BaTiO}_{3}$ particles (denoted by Pr. A, Pr. B, and Pr. C) in poly (methyl methacrylate) (PMMA) matrix were used for the performance improvement of capacitive properties of low-loss microwave capacitors. Special attention in this paper was in operation frequencies of mobile telecommunication devices, i.e., from 0.5 to $3 \mathrm{GHz}$, due to the amount of potential applications. The performance of capacitor structures was investigated with these new materials. This paper has been organized and presented from the computer modeling point of view by considering capacitor structures and emphasizing the modeling of RF characteristics of new materials. Section II presents the development of dielectric inks utilizing different shape particles as fillers. Section III describes a method to accurately characterize the dielectric composite materials based on interdigital-shaped capacitors. The results and discussion are in Section IV. Last, Section V provides the conclusion.

\section{Development of Dielectric InKs}

Solid barium hydroxide octahydrate, $\mathrm{Ba}(\mathrm{OH})_{2} \cdot 8 \mathrm{H}_{2} \mathrm{O}$, was reacted with sodium titanate slurry at $90{ }^{\circ} \mathrm{C}$ for 3 and $30 \mathrm{~h}$ to form sample Pr. A and Pr. C, respectively. With ion exchange reaction, the sodium ions in the titanate were replaced by barium ions forming small crystal size $\mathrm{BaTiO}_{3}$ [1]. The $\mathrm{BaTiO}_{3}$ slurry was filtered and washed (sodium OFF) with water, and the filter cake was dried at $110^{\circ} \mathrm{C}$. The dry sample was calcined in a rotary kiln at $800{ }^{\circ} \mathrm{C}$ for $1.5 \mathrm{~h}$. Then added

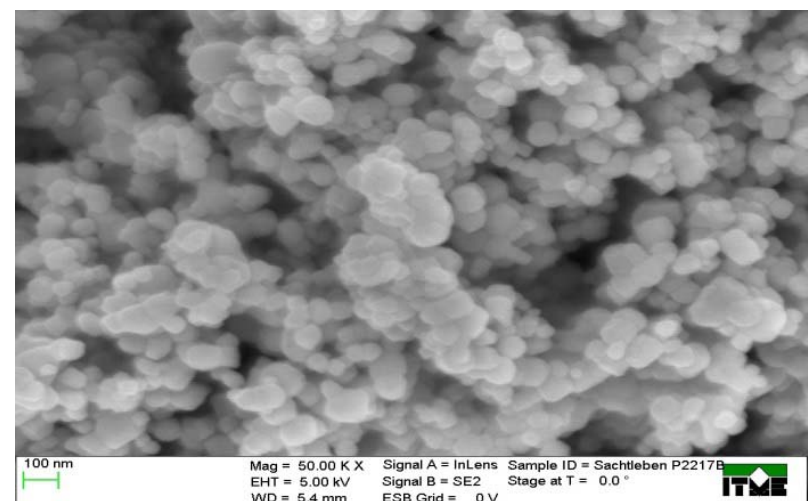

Fig. 1. FESEM picture of Pr. A. sample slurry at $90{ }^{\circ} \mathrm{C}$ for $3 \mathrm{~h}$ and calcinated at $800{ }^{\circ} \mathrm{C}$ (average size $90 \mathrm{~nm}$ ).

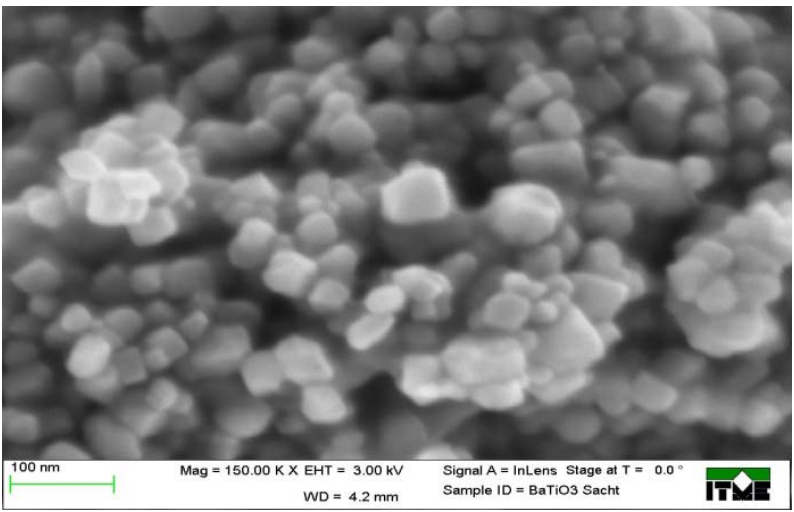

Fig. 2. Pr. C sample slurry at $90{ }^{\circ} \mathrm{C}$ for $30 \mathrm{~h}$ and calcinated at $800{ }^{\circ} \mathrm{C}$ (average size $150 \mathrm{~nm}$, dendrite structures).

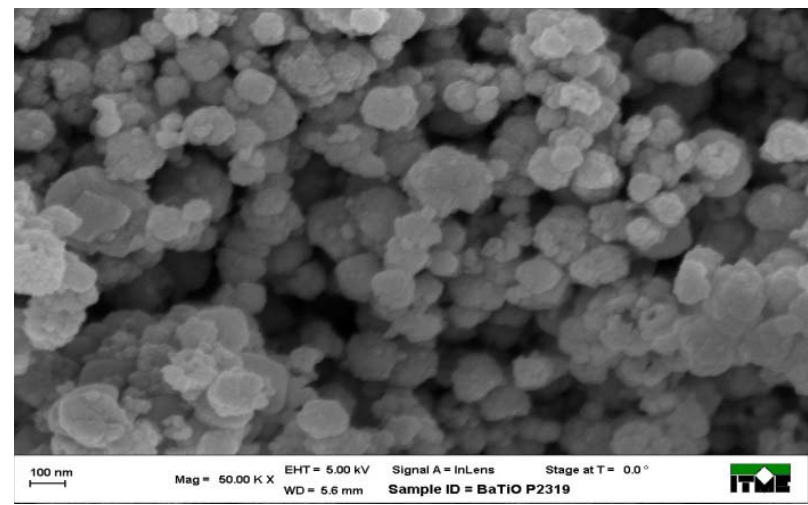

Fig. 3. Pr. B. sample slurry at $90{ }^{\circ} \mathrm{C}$ for $3 \mathrm{~h}$ and calcinated at $300{ }^{\circ} \mathrm{C}$ (average size $60 \mathrm{~nm}$ ).

into water, filtrated, washed with water, dryed, and dry milled. Morphology of the particles, which were characterized by field emission scanning electron microscopy (FESEM), is shown in Fig. 1 (Pr. A) and Fig. 2 (Pr. C).

In the case of Pr. B sample with FESEM picture in Fig. 3, solid barium hydroxide monohydrate, $\mathrm{Ba}(\mathrm{OH})_{2} \cdot \mathrm{H}_{2} \mathrm{O}$, and strontium hydroxide octahydrate, $\mathrm{Sr}(\mathrm{OH})_{2} \cdot 8 \mathrm{H}_{2} \mathrm{O}$, were reacted with sodium titanate slurry at $90{ }^{\circ} \mathrm{C}$ for $3 \mathrm{~h}$. With ion exchange reaction, the sodium ions in the titanate were replaced by barium and strontium ions forming small crystal size barium strontium titanate. Similarly, the slurry was filtered and washed (sodium OFF) with water, and the filter cake was dried at $110{ }^{\circ} \mathrm{C}$. In this case, the dry sample was calcined in a rotary kiln at $300{ }^{\circ} \mathrm{C}$ for $1.5 \mathrm{~h}$. Afterward, it was added into water, 
TABLE I

COMPOSITIONS WiTH $\mathrm{BaTiO}_{3}$ INKS

\begin{tabular}{|c|c|c|c|c|c|c|}
\hline \multirow[b]{2}{*}{ Filler } & \multicolumn{6}{|c|}{$\mathrm{BaTiO}_{3}$} \\
\hline & $\begin{array}{c}\text { mass } \\
{[\mathrm{g}]}\end{array}$ & $\begin{array}{l}\text { wt. } \\
\%\end{array}$ & $\begin{array}{c}\text { mass } \\
{[\mathrm{g}]}\end{array}$ & $\begin{array}{c}\text { wt. } \\
\%\end{array}$ & $\begin{array}{c}\text { mass } \\
{[\mathrm{g}]}\end{array}$ & $\begin{array}{l}\text { wt. } \\
\%\end{array}$ \\
\hline Pr. A & 5 & 67.4 & - & & - & - \\
\hline Pr. B & - & - & 5 & 66.3 & - & - \\
\hline Pr. C & - & - & - & - & 5 & 67.1 \\
\hline PMMA & 1.8 & 24.2 & 1.8 & 23.9 & 1.8 & 24.2 \\
\hline $\mathrm{OKB}$ & 0.6 & 8.3 & 0.7 & 9.8 & 0.65 & 8.7 \\
\hline \multicolumn{7}{|c|}{ Final layer contains $3.5 \mathrm{wt} . \%$ of polymer } \\
\hline
\end{tabular}

filtrated, washed with water, dryed, and dry milled. Molar ratio of the $\mathrm{Sr} / \mathrm{Ba}$ in the material was $2: 5$, and the amount of elements was measured by utilizing X-ray fluorescent.

Compositions of screen-printed inks with $\mathrm{BaTiO}_{3}$ are reported in Table I, where the vehicles composition is $10 \mathrm{wt} \%$ of PMMA $\left(M_{w} \sim 350000\right)$ and diethylene glycol n-butyl ether acetate solvent denoted as OKB.

It is noteworthy to mention that the silver conductor layer with thickness of $15 \mu \mathrm{m}$ was printed on the substrate adopting screen printing techniques. Similarly, the same screen printing technique was utilized to create patterns on the top of the conductive pattern forming interdigital-shaped capacitors, which were used for the characterization of the $\mathrm{BaTiO}_{3}$ composite ink. The $\mathrm{BaTiO}_{3}$ composite inks were printed on the capacitor structures with 200 mesh stainless steel screens and cured in $120{ }^{\circ} \mathrm{C}$ for $30 \mathrm{~min}$. Alumina $\left(96 \% \mathrm{Al}_{2} \mathrm{O}_{3}\right)$ was used for stable substrate with high accuracy and repeatability.

\section{MEASUREMENT AND CHARACTERIZATION OF PRINTED DiELECTRIC POLYMER LAYERS}

In this section, a dielectric material characterization method based on interdigital-shaped capacitor is presented. The aim of the characterization was to obtain the frequency dependent permittivity $\varepsilon_{r}$ and dielectric loss tangent of the printed composite layers by simulating the whole component structures including the composite materials. Thus, the characterization takes into account the final form of the material behavior (film thickness, density, surface roughness) including fabrication tolerance and processing parameters that can be different when analyzed using $\mathrm{TE}_{01 \delta}$ dielectric resonator method in [29]. To accurately define the characteristics of the new materials, three sets of interdigital-shaped capacitor structures with different number of linewidths and fingers were fabricated and measured. Three different shapes were used for statistical reasons, and the material properties can be extracted from the capacitor component when components have been fabricated with and without the $\mathrm{BaTiO}_{3}$ ink filling. Thus, the order of research involved the design, fabrication, and measurement of capacitor circuits. It followed by the components simulation and finally simulated the materials on the components to extract the electrical properties of the materials.

The detailed capacitor component structures, with and without the composite layers, are given in Fig. 4. The components were designed in a $4 \times 4 \mathrm{~mm}^{2}$ area. Linewidths and number of fingers for the interdigital capacitors were $180 \mu \mathrm{m}$ and five

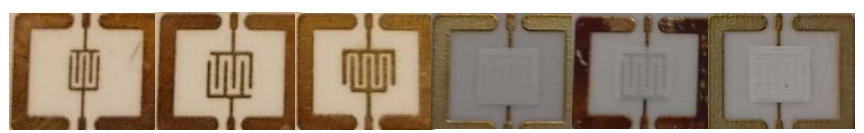

(a)

(b)

(c)

(d)

(e)

(f)

Fig. 4. Different screen printed interdigital capacitor component types in a $4 \times 4 \mathrm{~mm}^{2}$ area with linewidth of (a) $180 \mu \mathrm{m}$ and five fingers, (b) $200 \mu \mathrm{m}$ and six fingers, and (c) $240 \mu \mathrm{m}$ and seven fingers. The structures of the printed dielectric polymer layers on the capacitor components indicated as (d) Pr. A filler, (e) Pr. B filler, and (f) Pr. C filler.

fingers, $200 \mu \mathrm{m}$ and six fingers, and $240 \mu \mathrm{m}$ and seven fingers for component type a, b, and c [see Fig. 4(a)-(c)], respectively. In Fig. 4(d)-(f), the thickness of the composite layers printed on the capacitor varies from 33 to $39 \mu \mathrm{m}, 20$ to $31 \mu \mathrm{m}$, and 23 to $28 \mu \mathrm{m}$ for Pr. A, Pr. B, and Pr. C shape filler layers, respectively.

Furthermore, effects of varied thickness of the dielectric materials pasted on the top of the fabricated capacitor structures were considered for the permittivity and loss tangent calculations during the simulation of all the component types. The values of the permittivity and dielectric loss tangent were calculated by simulating the interdigital-shaped capacitor structures with and without the composite materials with an electromagnetic solver. In this paper, CST Microwave Studio (MWS) was utilized. An initial guess value was set for both the dielectric constant and the loss tangent. Both the measured and simulated magnitudes of S-parameters at resonant frequency was compared until the simulated parameters were properly correlated with that of measured parameters. Thus, an optimized value of dielectric and loss tangent was obtained. As a comparison, Han et al. [30] had reported a meander-shaped inductor component for nanocomposite material characterization. The material properties extraction method and fabrication technique, described in [30], which have the benefits of material usage minimization and uncomplicated fabrication, are similar in this paper. Since the electrical properties of capacitor component depend on the physical dimension of the component and its material properties, essentially, the capacitance and $Q$-factor of the passive component with and without the ink were also measured.

The properties of the capacitors were measured with $8530 \mathrm{~A}$ Agilent Technologies vector network analyzer, and the calibration of the measurement system was performed using the line-reflect-reflect-match method. The measurement results were obtained in the frequency range from 0.5 to $3 \mathrm{GHz}$ as the component self-resonance was limiting the highest applicable frequencies. Both finite-element method (FEM) design and circuit model simulations of the interdigital-shaped capacitors (Fig. 5) were performed using CST MWS. The first-order circuit model presented in Fig. 5(b) describes the characteristics of the interdigital capacitor type $b$ with six fingers given in Fig 5(b). The parallel elements of the circuit model consist of $C$ sub1 and $2(0.001 \mathrm{pF})$, which represent the capacitive coupling between the conductor and the substrate. In addition, the series branch of the circuit consists of parasitic series inductance $L_{S}(3.8 \mathrm{nH})$, series resistance $R_{S}(5 \Omega)$, and the desired set capacitance $C$, which value varies with different ink layer materials. Finally, the results of both the FEM and the circuit model were compared to that 
TABLE II

Properties of DifFERENT CoMponent TyPes With AND Without DiELECTRIC INK LAYER

\begin{tabular}{|c|c|c|c|c|c|c|c|c|c|c|c|c|c|c|c|c|}
\hline $\begin{array}{l}\text { Component } \\
\text { types }\end{array}$ & \multicolumn{8}{|c|}{ Measured capacitance, $\mathrm{C}(\mathrm{pF})$} & \multicolumn{8}{|c|}{ Measured Q-Factor } \\
\hline & \multicolumn{2}{|c|}{ Reference } & \multicolumn{2}{|c|}{ Pr. A } & \multicolumn{2}{|c|}{ Pr. B } & \multicolumn{2}{|c|}{ Pr. C } & \multicolumn{2}{|c|}{ Reference } & \multicolumn{2}{|c|}{ Pr. A } & \multicolumn{2}{|c|}{ Pr. B } & \multicolumn{2}{|c|}{ Pr. C } \\
\hline & $1 \mathrm{G}$ & $2 \mathrm{G}$ & $1 \mathrm{G}$ & $2 \mathrm{G}$ & $1 \mathrm{G}$ & $2 \mathrm{G}$ & $1 \mathrm{G}$ & $2 \mathrm{G}$ & $1 \mathrm{G}$ & $2 \mathrm{G}$ & $1 \mathrm{G}$ & $2 \mathrm{G}$ & $1 \mathrm{G}$ & $2 \mathrm{G}$ & $2 \mathrm{G}$ & $2 \mathrm{G}$ \\
\hline $\mathrm{b}$ & 0.6 & 1.0 & 1.0 & 2.6 & 0.8 & 1.9 & 0.8 & 1.7 & 43.4 & 17.4 & 34.0 & 8.5 & 37.1 & 11.0 & 40.0 & 12.5 \\
\hline $\mathrm{c}$ & 0.8 & 2.0 & 1.4 & 18.1 & 1.2 & 7.0 & 1.2 & 5.1 & 41.0 & 12.0 & 40.0 & 1.7 & 33.5 & 4.0 & 36.5 & 5.7 \\
\hline
\end{tabular}

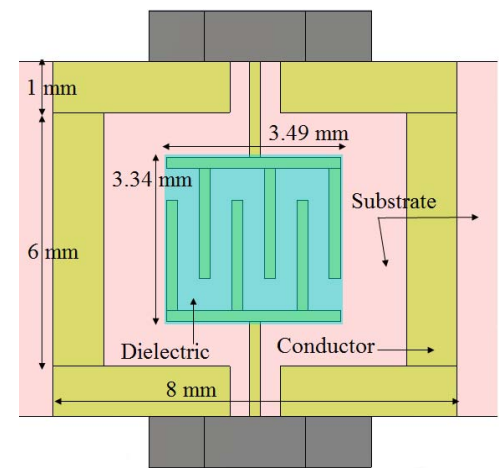

(a)

Fig. 5. (a) Model of the type b capacitor for the FEM analysis. (b) First-order circuit model simulations of capacitor type b (see Fig. 4) using CST MWS.

of the measurement results, and the dielectric polymer layer properties were obtained from the results.

\section{RESULTS AND DiscUSSION}

Two-port scattering parameters (S-parameters) graph results of measurement, FEM design, and circuit model are presented in Fig. 6 by means of capacitor component type b [see Fig. 4(b)]. Fig. 6(a) shows reference without filling layer, Fig. 6(b) shows filling layer Pr. A, Fig. 6(c) shows filling layer Pr. B, and Fig. 6(d) shows filling layer Pr. C, taken at frequency from 0.5 to $3 \mathrm{GHz}$. It can be noticed that the frequency responses are relatively close to each other in Fig. 6(a)-(d) behaving such as capacitor's typical characteristic before its self-resonance frequency. As shown in the graphs, the measurement response characteristics are in agreement $\left(S_{12}\right.$ inaccuracy below 5\%) with both the CST FEM design and the circuit model. From S-parameters of the measurement results, electrical parameters of capacitor, such as capacitance $C$ and $Q$-factor, were extracted by admittance $(Y)$ matrix parameter calculations. The $Q$-factor values for capacitor were calculated from matrix parameters as

$$
Q=\left|\frac{\operatorname{Im}\left(Y_{21}\right)}{\operatorname{Re}\left(Y_{21}\right)}\right| \text {. }
$$

Likewise, the capacitance values $(\mathrm{pF})$ of the capacitor were realized by using (2), where $f$ is the frequency

$$
C=\frac{10^{12}}{2 \pi f \times \operatorname{Im}\left(1 / Y_{21}\right)} \mathrm{pF} .
$$

Plots of the measurement results of capacitance and $Q$-factor for component type $\mathrm{b}$ are reported as a function of frequency

in Fig. 7(a) and (b). The capacitance values started from $0.5 \mathrm{pF}$ at $0.5 \mathrm{GHz}$ increasing up to $0.8 \mathrm{pF}$ with printed filling. The self-resonance of the component $\mathrm{b}$ was around $2.9 \mathrm{GHz}$ the reference component, and it decreased to 2.6, 2.55, and $2.4 \mathrm{GHz}$ with filling Pr. C, Pr. B, and Pr. A, respectively. The $Q$-factors started from 85 at $0.5 \mathrm{GHz}$ decreasing down to 65 with printed layer. $Q$-factor decreased to zero at the self-resonance according to (1). The component types a and c (see Fig. 4) also followed similar patterns.

In Table II, all the three component types (a, b, and c) are presented on the first column followed by eight columns presenting reference and three printed filling materials measured capacitances. Next eight columns are presenting measured $Q$-factors of corresponding cases. The properties are presented at 1 and $2 \mathrm{GHz}$, which are widely used in telecommunications frequencies. The capacitance values measured at $1 \mathrm{GHz}$ were from 0.4 to $0.8 \mathrm{pF}$ with reference components. However, the capacitance values were found to increase from 0.6 to $1.4 \mathrm{pF}$ with printed layers (Pr. A-C). As observed from Table II, the printed layer, acting as filler materials, improved the capacitance values where Pr. A ink layer had the highest effect. In addition, the capacitance values measured at $2 \mathrm{GHz}$ were from 0.7 to $2 \mathrm{pF}$ in reference components. With printed layer materials, the capacitance values increased significantly from 1.2 to $18.1 \mathrm{pF}$. Again, at $2 \mathrm{GHz}$, Pr. A material had the highest effect. Materials (Pr. A-C) improved the capacitance at $2 \mathrm{GHz}$ more than at $1 \mathrm{GHz}$. The reason can be attributed to the self-resonance, which increased the capacitive values at $2 \mathrm{GHz}$, especially with component type c that had the highest capacitance. The $Q$-factor values $(1 \mathrm{GHz})$ were from 41 to 45 with no materials. With materials (Pr. A-C), the values were from 23 to 42 . All materials decreased the $Q$-factor. Among the materials, Pr. $\mathrm{C}$ has the highest $Q$-factor. Measured at $2 \mathrm{GHz}$, the $Q$-factor values were from 12 to 19 with no materials. With materials, the values were from 1.7 to 14.5 . Similarly, Pr. C material has the highest $Q$-factor. Notably, the self-resonance decreased the $Q$-factor at $2 \mathrm{GHz}$, especially with component type c.

In Fig. 8, the simulated relative permittivity values for the different ink layers across frequency band 0.5 to $3 \mathrm{GHz}$ are presented. The permittivity results extracted for each of the component types were based on the method explained in Section III. It is noticed in Fig. 8 that the permittivity plots for each of the ink materials decreased at a constant rate as the frequency increases. The reason is that constant-fittan-delta model was utilized for the simulation. In the future 


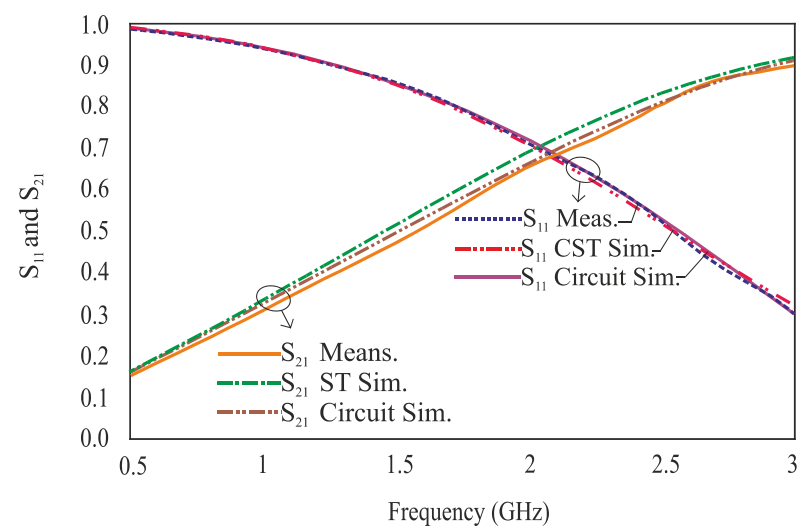

(a)

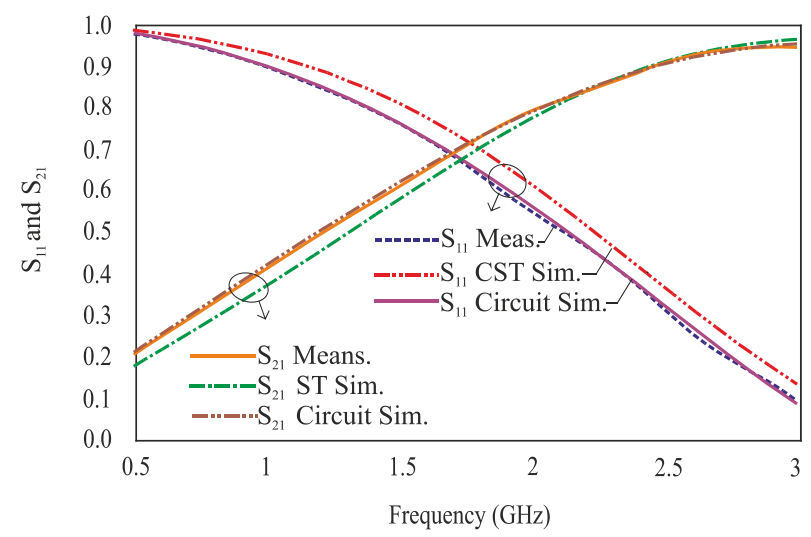

(c)

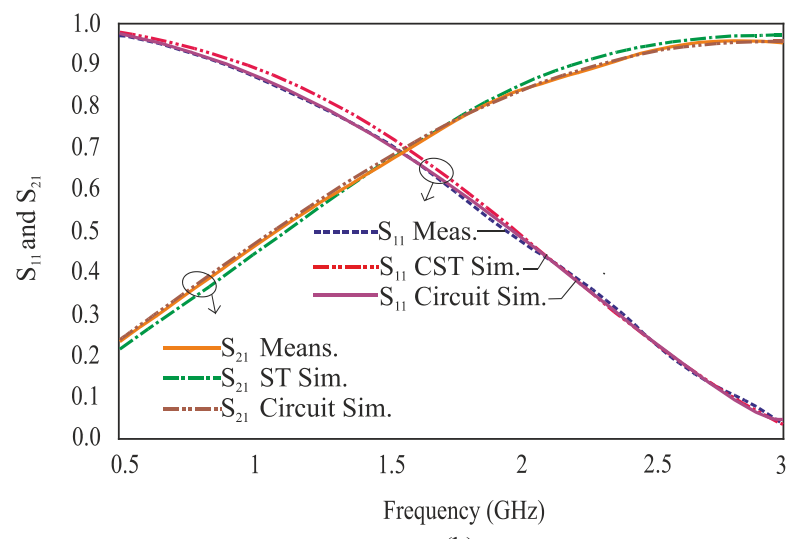

(b)

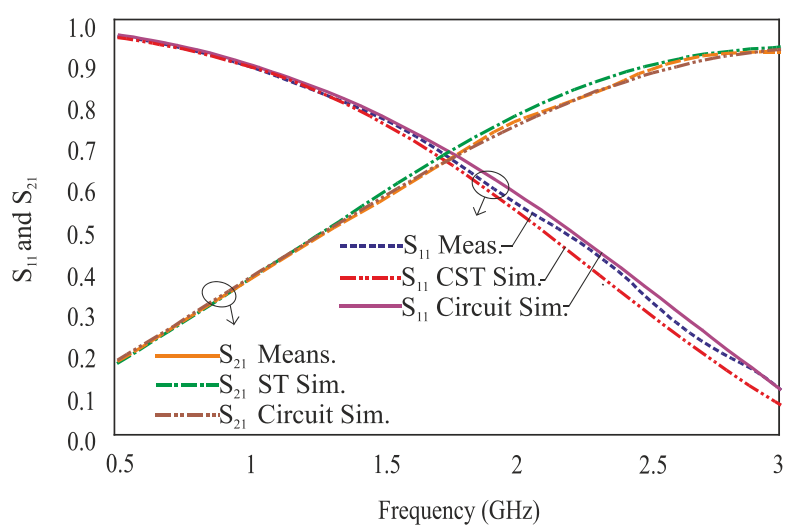

(d)

Fig. 6. Linear S-parameters of component type b, given in Fig. 4. (a) Without filling layer (reference). (b) With filling layer Pr. A shape. (c) With Pr. B shape. (d) With Pr. $\mathrm{C} \mathrm{BaTiO}_{3}$ filled layers.

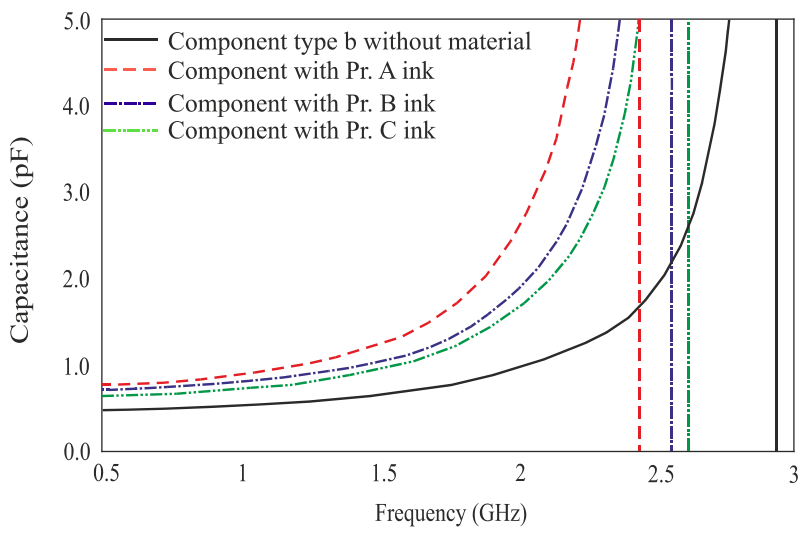

(a)

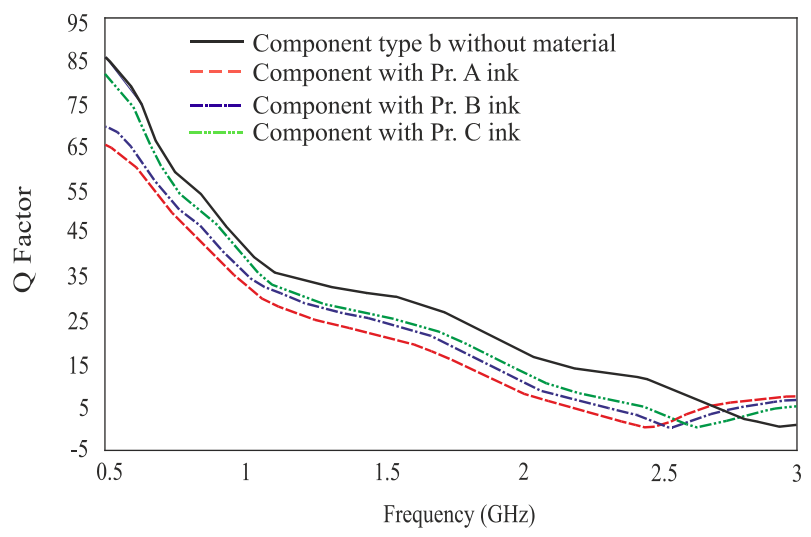

(b)

Fig. 7. Frequency dependence of measured (a) capacitance and (b) $Q$-factor results for component type b.

project, it will be on plan that other nonlinear models will be considered, and in that case, the material would be simulated together with the component structures for higher frequencies, up to $6 \mathrm{GHz}$, a useful frequency band for $5 \mathrm{G}$ telecommunication applications. It is found during the simulation that the variation of ink layer thickness pasted on the top of the capacitor affected the performance of the permittivity properties. The lower the thickness of the material layer, the higher the values of permittivity. By considering the minimum values of the measured ink layer thicknesses of 33, 31, and $23 \mu \mathrm{m}$ for Pr. A, Pr. B, and Pr. C, respectively, the extracted relative permittivity values of 30,25 , and 27 were obtained for all the component types, taken at $2 \mathrm{GHz}$. The variation of permittivity values as the thickness increases is about $\pm 8 \%$ at the predefined values of the measured material thickness that is in the range of similar studies presented in the field. It is noticed from Fig. 8 that Pr. A has the highest relative permittivity while Pr. B has the lowest value. This may be due to the presence of higher ceramic filler contents of $67.4 \mathrm{wt} \%$ (see Table I) in Pr. A material than that of 66.3 and $67.1 \mathrm{wt} \%$ in Pr. B and Pr. C, respectively. Similar trend can be observed in [15] and [24] as relative permittivity and loss tangent increased with increasing 


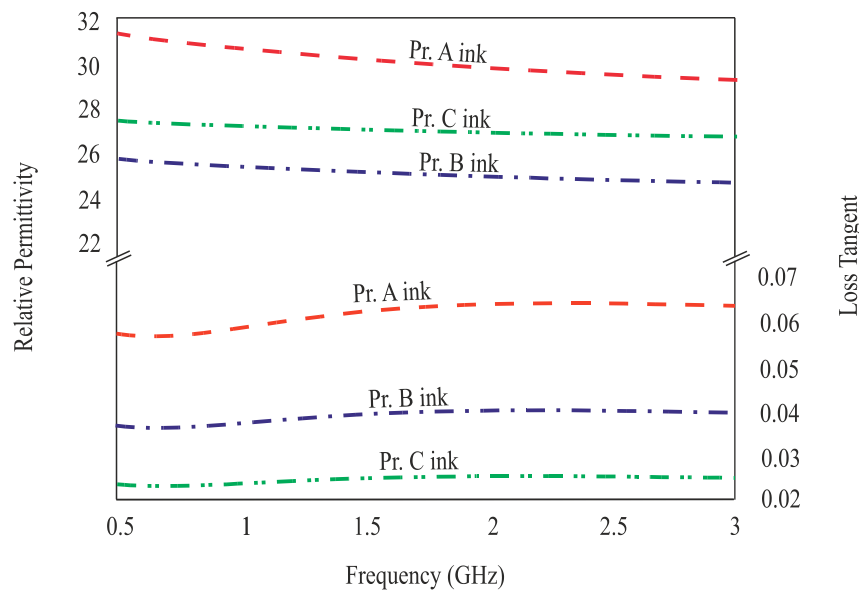

Fig. 8. Characterized relative permittivity and loss tangent as a function of frequency.

$\mathrm{BaTiO}_{3}$ contents in butyl rubber-BaTiO 3 composites. It has been reported likewise in [31] that the dielectric constant of $\mathrm{BaTiO}_{3}$-polyvinylidene fluoride composite film increases with an increase in the particle volume fraction from 20 to $30 \mathrm{vol} . \%$. A similar $\mathrm{BaTiO}_{3}$ particle content effect resulted to an increase in the dielectric constant of the materials.

The loss tangents for the ink layer materials printed on component type b [see Fig 4(e)] were likewise investigated. The same method in Section III was considered for loss tangent properties extraction. As shown in Fig. 8, the loss tangents of all the three ink materials were below 0.08 . Typically, in manufacturing of electronic components like a capacitor, the magnitude of loss tangent should be as low as possible. The simulated loss tangent values of the three inks taken at $2 \mathrm{GHz}$ were $0.065,0.040$, and 0.025 for Pr. A, Pr. B, and Pr. C, respectively. The results revealed appreciable low loss performance for all the ink materials. Among the different inks, Pr. C shape particle had the lowest loss tangent value. This characteristic behavior exhibited in the Pr. C ink material might be attributed to its filler size and content. When compared with the $\mathrm{BaTiO}_{3} /$ Polymer composites in [28] taken at $2 \mathrm{GHz}$, the loss tangent of the composite materials obtained in this paper, especially with $\operatorname{Pr}$. C, is lower than the loss tangent of 0.04 for $\mathrm{BaTiO}_{3} / \mathrm{TDDMA}, 0.05$ for $\mathrm{BaTiO}_{3} / \mathrm{TMPTA}$, and 0.2 for $\mathrm{BiTiO}_{3} / \mathrm{PEGDA}$ composites in [28] at constant $30 \%$ of $\mathrm{BaTiO}_{3}$.

The above results suggested that as the volume fraction of the filler contents in the composite material ( $\left.\mathrm{PMMA} / \mathrm{BaTiO}_{3}\right)$ varied, the dielectric properties and loss tangent of the material can be manipulated based on the area of applications. Thus, for high-frequency application where loss tangent should be as low as possible, Pr. C shape particle with the minimum loss tangent has higher preference over Pr. A and Pr. B. On the other hand, Pr. A would be highly considered among the ink materials for microwave applications of electronic components that require moderate loss tangent but high properties of capacitance and permittivity.

\section{CONClusion}

In this paper, characterization of a novel composite material using printed interdigital-shaped capacitor structures was presented. Inks consisting of Pr. A-, Pr. B-, and Pr. C-shaped $\mathrm{BaTiO}_{3}$ particles in PMMA matrix were developed and printed on the top of the capacitors for the extraction of the material properties. The dielectric properties of the composite materials were influenced by the thickness variation of the ink layers on the capacitor structures. The results show moderate values of relative permittivity 30 for inks with Pr. A shape at $67.4 \mathrm{wt} \%, 25$ for Pr. B shape at $66.3 \mathrm{wt} \%$, and 27 for Pr. C shape at $67.1 \mathrm{wt} \%$ of $\mathrm{BaTiO}_{3}$ particles at $2 \mathrm{GHz}$. In addition, low dielectric losses of 0.065 , 0.040 , and 0.025 were obtained, respectively. These new capacitor composite materials would be suitable for printed application in mobile telecommunication systems, especially in the frequency range of 0.5 to $3 \mathrm{GHz}$. The results further suggested that as the volume fraction of the filler contents in the composite materials varied, the dielectric properties and loss tangent of the materials can be manipulated in accordance to the area of applications.

\section{REFERENCES}

[1] V. Subramanian et al., "Printed electronics for low-cost electronic systems: Technology status and application development," in Proc. Eur. Solid-State Circuits Conf. (ESSCIRC), Sep. 2008, pp. 17-24.

[2] MarketsandMarkets. (Jan. 2016). Printed Electronics Market by Material (Substrates \& Inks), Technology (Screen, Gravure, Inkjet \& Flexography), Application (Displays, Sensors, OLEDs \& PVs), and Geography-Analysis and Forecast to 2013-2020. [Online]. Available: http://www.marketsandmarkets.com/Market-Reports/printedmarket-197.html

[3] B. Crone et al., "Electronic sensing of vapors with organic transistors," Appl. Phys. Lett., vol. 78, no. 15, pp. 2229-2231, Jan. 2001.

[4] F. Liao, C. Chen, and V. Subramanian, "Organic TFTs as gas sensors for electronic nose applications," Sens. Actuators B, Chem., vol. 107, no. 2, pp. 849-855, Dec. 2004.

[5] T. Someya, T. Sekitani, S. Iba, Y. Kato, H. Kawaguchi, and T. Sakurai, "A large-area, flexible pressure sensor matrix with organic field-effect transistors for artificial skin applications," Proc. Nat. Acad. Sci. USA, vol. 101, no. 27, pp. 9966-9970, 2004.

[6] A. A. Babar, V. A. Bhagavati, L. Ukkonen, A. Z. Elsherbeni, P. Kallio, and L. Sydänheimo, "Performance of high-permittivity ceramic-polymer composite as a substrate for UHF RFID tag antennas," Int. J. Antennas Propag., vol. 2012, no. 10, Apr. 2012, Art. no. 905409.

[7] V. Subramanian et al., "Progress toward development of all-printed RFID tags: Materials, processes, and devices," Proc. IEEE, vol. 93, no. 7, pp. 1330-1338, Jul. 2005.

[8] Y. J. Chan, C. P. Kung, and Z. Pei, "Printed RFID: Technology and application," in Proc. IEEE Int. Workshop Radio-Frequency Integr. Technol., vol. 10. Nov./Dec. 2005, pp. 139-141.

[9] S. Steudel, S. De Vusser, K. Myny, M. Lenes, J. Genoe, and P. Heremans, "Comparison of organic diode structures regarding high-frequency rectification behavior in radio-frequency identification tags," J. Appl. Phys., vol. 99, no. 11, p. 114519, Jun. 2006.

[10] F. C. Krebs, "Fabrication and processing of polymer solar cells: A review of printing and coating techniques," Solar Energy Mater. Solar Cells, vol. 93, no. 4, pp. 394-412, Dec. 2008.

[11] M. Haghzadeh, C. Armiento, and A. Akyurtlu, "All-printed conformai electronically scanned phased array," in IEEE MTT-S Int. Microw. Symp. Dig., Honololu, HI, USA, Jun. 2017, pp. 521-524.

[12] J. Castro, E. Rojas, A. Ross, T. Weller, and J. Wang, "High- $k$ and low-loss thermoplastic composites for fused deposition modeling and their application to 3D-printed Ku-band antennas," in IEEE MTT-S Int. Microw. Symp. Dig., San Francisco, CA, USA, May 2016, pp. 1-4.

[13] H. Sirringhaus, N. Tessler, and R. H. Friend, "Integrated optoelectronic devices based on conjugated polymers," Science, vol. 280, pp. 1741-1744, Jun. 1998.

[14] M. Nelo, A. Sowpati, V. K. Palukuru, J. Juuti, and H. Jantunen, "Formulation of screen printable cobalt nanoparticle ink for high frequency applications," Prog. Electromagn. Res., vol. 110, pp. 253-266, Oct. 2010. 
[15] J. Chameswary and M. T. Sebastian, "Preparation and properties of $\mathrm{BaTiO}_{3}$ filled butyl rubber composites for flexible electronic circuit applications," J. Mater. Sci., Mater. Electron., vol. 26, no. 7, pp. 4629-4637, Feb. 2015.

[16] D. C. Kulkarnia, U. B. Lonkarb, and V. Puria, "High-frequency permeability and permittivity of $\mathrm{Ni}_{x} \mathrm{Zn}_{(1-x)} \mathrm{Fe}_{2} \mathrm{O}_{4}$ thick film," J. Magn. Magn. Mater., vol. 320, pp. 1844-1848, Jun. 2008.

[17] Y. C. Li, S. C. Tjong, and R. K. Y. Li, "Dielectric properties of binary polyvinylidene fluoride/barium titanate nanocomposites and their nanographite doped hybrids," Exp. Polym. Lett., vol. 5, no. 6, pp. 526-534, Dec. 2010.

[18] R. F. Barzic, A. I. Barzic, and G. Dumitrascu, "Percolation effects on dielectric properties of polystyrene/BaTiO 3 nanocomposites," U.P.B. Sci. Bull. A, vol. 76, no. 3, p. 225, Jan. 2014.

[19] M. D. Toomey, K. Gao, G. P. Mendis, E. B. Slamovich, and J. A. Howarter, "Hydrothermal synthesis and processing of barium titanate nanoparticles embedded in polymer films," ACS Appl. Mater. Interfaces, vol. 7, no. 51, pp. 28640-28646, Feb. 2015.

[20] H.-I. Hsiang, K.-Y. Lin, F.-S. Yen, and C.-Y. Hwang, "Effects of particle size of $\mathrm{BaTiO}_{3}$ powder on the dielectric properties of $\mathrm{BaTiO}_{3}$ /polyvinylidene fluoride composites," J. Mater. Sci., vol. 36, no. 15 , pp. 3809-3815, Aug. 2001.

[21] M. Saleem, J. S. Song, S. J. Jeong, M. S. Kim, S. Yoon, and I. S. Kim, "Dielectric response on microwave sintered $\mathrm{BaTiO}_{3}$ composite with Ni nanopowder and paste," Mater. Res. Bull., vol. 64, pp. 380-385, Apr. 2015.

[22] Y. Yashchyshyn et al., "Tunable ferroelectric ceramic-polymer composites for sub-THz applications," in Proc. 43rd Eur. Microw. Conf., Nuremberg, Germany, Oct. 2013, pp. 676-679.

[23] Y. W. Cho, T. S. Hyun, and S. K. Choi, "Microwave dielectric properties of ferroelectric $\mathrm{BaTiO}_{3}$ thin film," J. Electroceram., vol. 13, nos. 1-3, pp. 251-255, Jul. 2004.

[24] S.-F. Wang, Y.-R. Wang, K.-C. Cheng, and Y.-P. Hsaio, "Characteristics of polyimide/barium titanate composite films," Ceram. Int., vol. 35 , no. 1, pp. 265-268, 2007.

[25] D. Balaraman, P. M. Raj, R. Tanikella, P. Kohl, S. Bhattacharya, and R. R. Tummala, "Low temperature $\left(<100{ }^{\circ} \mathrm{C}\right)$ hydrothermal synthesis of high K-low loss $\mathrm{BaTiO}_{3}$ films for integral capacitors," in Proc. 4th Electron. Packag. Technol. Conf., Singapore, Dec. 2002, pp. 79-84.

[26] T. Siponkoski, M. Nelo, J. Peräntie, J. Juuti, and H. Jantunen, "BaTiO $3-\mathrm{P}(\mathrm{VDF}-\mathrm{TrFE})$ composite ink properties for printed decoupling capacitors," Compos. B, Eng., vol. 70, pp. 201-205, Mar. 2015.

[27] S. Lei, H. Fan, and W. Chen, "Effects of $\mathrm{CaO}-\mathrm{B}_{2} \mathrm{O}_{3}$ glass addition on the low-temperature sintering and cation ordering in $\mathrm{Sr}_{x} \mathrm{La}_{(1-x)} \mathrm{Ti}_{x} \mathrm{Al}_{(1-x)} \mathrm{O}_{3}$ ceramics," J. Alloys Compounds, vol. 632, pp. 78-86, May 2015

[28] R. Popielarz, C. K. Chiang, R. Nozaki, and J. Obrzut, "Dielectric properties of polymer/ferroelectric ceramic composites from $100 \mathrm{~Hz}$ to 10 GHz," Macromolecules, vol. 34, no. 17, pp. 5910-5915, Jun. 2001.

[29] B. Riddle, J. Baker-Jarvis, and J. Krupka, "Complex permittivity measurements of common plastics over variable temperatures," IEEE Trans. Microw. Theory Techn., vol. 51, no. 3, pp. 727-733, Mar. 2003.

[30] K. Han et al., "Extraction of electrical properties of nanomagnetic materials through meander-shaped inductor and inverted-F antenna structures," in Proc. IEEE 62nd Electron. Compon. Technol. Conf. (ECTC), San Diego, CA, USA, May/Jun. 2012, pp. 1808-1813.

[31] Y. Kobayashi, T. Tanase, T. Tabata, T. Miwa, and M. Konno, "Fabrication and dielectric properties of the $\mathrm{BaTiO}_{3}$-polymer nano-composite thin films," J. Eur. Ceram. Soc., vol. 28, no. 1, pp. 117-122, Dec. 2008.

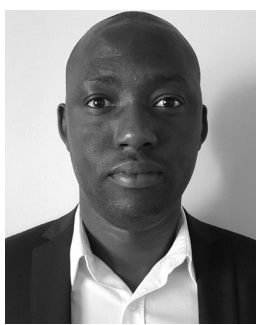

Omodara Gbotemi is a Doctoral Student with the Microelectronics Research Unit, University of Oulu, Oulu, Finland. His current research interests include antennas, electronic materials, and passive components for RF and microwave applications.

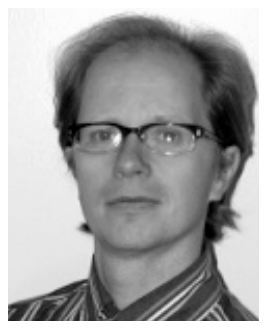

Sami Myllymäki is a Post-Doctoral Researcher and the Group Leader of the RELE Group, Microelectronics Research Unit, University of Oulu, Oulu, Finland. His current research interests include materials and component solutions for novel radio technology platforms.

Jani Kallioinen is currently with the Research and Development Division, Huntsman Pigments and Additives, Wynyard Park, U.K

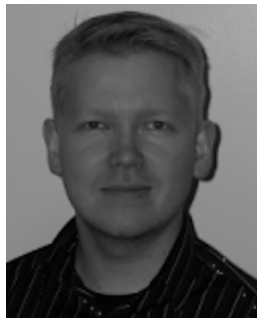

Jari Juuti received the D.Sc. degree in 2006

He joined as a Docent/Adjunct Professor in 2009. $\mathrm{He}$ is currently an Academy Research Fellow with the Academy of Finland, Finland. His current research interests include piezoelectrics and functional composites for telecom and printed electronics.

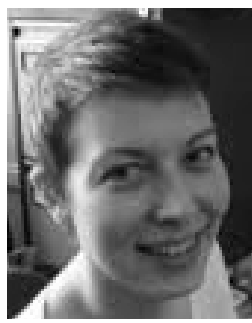

Merja Teirikangas is a Post-Doctoral Researcher with the Microelectronics Group, University of Oulu, Oulu, Finland. Her current research interests include the design and development of functional composite materials for high-frequency applications.

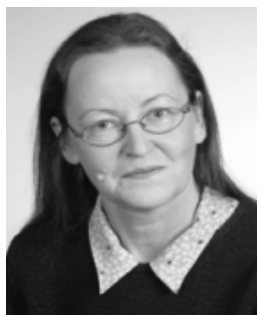

Heli Jantunen has been the Group Leader of the Electronics Materials, Packaging and Reliability Techniques Research Group, Infotech Oulu, Oulu, Finland, since 2004. She is currently a Professor and the Head of the Microelectronics Research Unit, University of Oulu, Oulu. Her current research interests include the design, development, synthesis, and implementation of electronics materials and their components for RF and microwave applications, as well as multifunctional micromodules. 


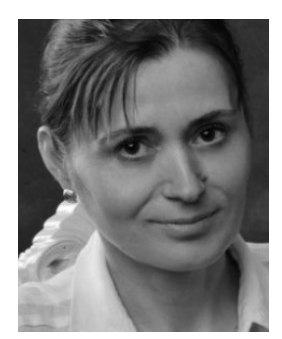

Marjeta Maček Kržmanc is currently a Senior Research Associate with the Advanced Materials Department, Jožef Stefan Institute, Ljubljana, Slovenia. Her current research interests include the synthesis of functional oxide materials with defined shape and phase, crystallization studies, and microwave dielectrics.

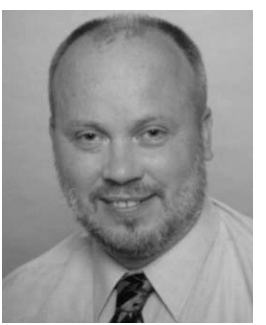

Danilo Suvorov is currently with the Advanced Materials Division, Jožef Stefan Institute, Ljubljana, Slovenia.

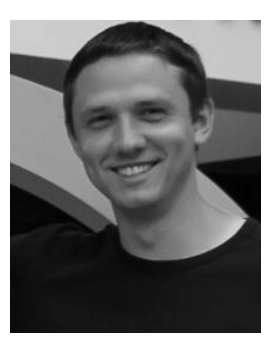

Marcin Sloma is an Assistant Professor with the Micro- and Nanotechnology Division, Warsaw University of Technology, Warsaw, Poland. His current research interests include printed electronics, microfabrication, 3-D printings, and nanomaterial applications in electronics.

Malgorzata Jakubowska is currently with the Microtechnology and Nanotechnology Division, Warsaw University of Technology, Warsaw, Poland. 